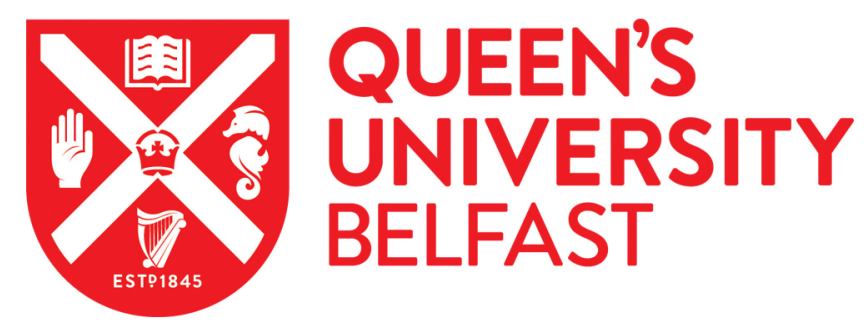

\title{
Linking oral bioaccessibility and solid phase distribution of potentially toxic elements in extractive waste and soil from an abandoned mine site:Case study in Campello Monti, NW Italy
}

Mehta, N., Cocerva, T., Cipullo, S., Padoan, E., Dino, G. A., Ajmone-Marsan, F., Cox, S. F., Coulon, F., \& De Luca, D. A. (2019). Linking oral bioaccessibility and solid phase distribution of potentially toxic elements in extractive waste and soil from an abandoned mine site:Case study in Campello Monti, NW Italy. Science of the Total Environment, 651, 2799-2810. https://doi.org/10.1016/j.scitotenv.2018.10.115, https://doi.org/10.1016/j.scitotenv.2018.10.115, https://doi.org/https://www.sciencedirect.com/science/article/pii/S0048969718339949

Published in:

Science of the Total Environment

\section{Document Version:}

Peer reviewed version

Queen's University Belfast - Research Portal:

Link to publication record in Queen's University Belfast Research Portal

\section{Publisher rights}

Copyright 2018 Elsevier.

This manuscript is distributed under a Creative Commons Attribution-NonCommercial-NoDerivs License

(https://creativecommons.org/licenses/by-nc-nd/4.0/), which permits distribution and reproduction for non-commercial purposes, provided the author and source are cited.

\section{General rights}

Copyright for the publications made accessible via the Queen's University Belfast Research Portal is retained by the author(s) and / or other copyright owners and it is a condition of accessing these publications that users recognise and abide by the legal requirements associated with these rights.

Take down policy

The Research Portal is Queen's institutional repository that provides access to Queen's research output. Every effort has been made to ensure that content in the Research Portal does not infringe any person's rights, or applicable UK laws. If you discover content in the Research Portal that you believe breaches copyright or violates any law, please contact openaccess@qub.ac.uk. 
Mining activities have led to the introduction of high levels of potentially toxic elements (PTE) concentrations in soils. This has attracted governmental and public attention due to their nonbiodegradable nature and hazards posed to human health and the environment. However, total concentrations of PTE are poor indicators of actual risk hazard to human health and can lead to overestimation of risk. In this study, oral bioaccessibility, the fraction available for absorption via oral ingestion, was used to refine human health risk assessment at an abandoned mine site from Campello Monti, north-west Italy. The solid phase distribution was performed to characterise the distribution and the behaviour of PTE within the extractive waste streams and impacted soil nearby. Mineralogical information was obtained from micro-XRF and SEM analysis used to identify elemental distibution maps. The results showed that the total concentrations of PTE were high, up to $7400 \mathrm{mg} / \mathrm{kg}$ for $\mathrm{Ni}$ due to the presence of parent material, however, only $11 \%$ was bioaccessible. Detailed analysis of the bioaccessible fraction (BAF) showed that $\mathrm{As}, \mathrm{Cu}$ and $\mathrm{Ni}$ varied from 7 to inform the risk assessment of abandoned mine sites.

Keywords: abandoned mine site, oral bioaccessbility, potentially toxic elements (PTE), risk assessment, solid phase distribution.

\section{Introduction}

Since the onset of industrial revolution, mining and smelting activities have been at forefront of economic development of many countries. Mining activities generate employment, while also 
producing a wide variety of minerals that can have countless uses in various contexts (Ono et al., 2016 ; Dino et al., 2018a). Yet, mining and dressing activities have resulted in the generation of large quantities of waste and degraded soils. After the closure of mining activities, these waste dumps were abandoned, resulting in poor management and maintenance. Further to this, the degraded soils, waste dumps and tailings are often geotechnically unstable and sources of contamination by PTE (Gál et al., 2007). As PTE tend to persist in the environment, these extractive waste dumps and soils often become a matter of concern for human health (Lim et al., 2009).

There is growing awareness and concern about the harmful effects of elevated concentrations of toxic elements on human health (Golia et al., 2008). However, there is a growing evidence that an elevated concentration of elements may not be indicative of the actual damaging effects. Consequently, it has been proposed that bioavailable concentrations should be used to inform human health risk assessment (HHRA). Bioavailable concentration is the concentration of the contaminants reaching to the systemic circulation and thereby the remainder of the body (Oomen, 2000). However, measuring bioavailability in-vivo is a difficult and lengthy procedure (Maddaloni et al., 1998). Therefore, a number of in-vitro bioaccessibility methods have been developed to measure the oral bioaccessibility of a contaminant (Cox et al., 2013). The oral bioaccessible fraction is defined as the fraction that, after ingestion, may be mobilized into the gut fluids (chyme). Bioaccessible concentration is greater than or equal to the bioavailable concentration and can be used as a conservative measure to the bioavailability for HHRA (Paustenbach, 2000).

The present research used the unified BARGE method (UBM) developed by the Bioaccessibility Research Group of Europe (BARGE) for measuring the oral bioaccessibility of contaminants in extractive waste and soils from abandoned mining sites. The UBM method has been validated against in vivo studies for $\mathrm{As}, \mathrm{Cd}$ and $\mathrm{Pb}$ (Denys et al., 2012) and has been used to provide guidance data on a wider range of chemical elements to facilitate inter-laboratory trials (Hamilton et al., 2015). Therefore, many studies have used the UBM method to assess 
contamination due to PTE in mining affected areas. For example, Pelfrêne et al., (2012) quantified bioaccessible concentrations of $\mathrm{Cd}, \mathrm{Pb}$ and $\mathrm{Zn}$ as $78 \%, 32 \%$, and $58 \%$ respectively on smeltercontaminated agricultural soils in a coal mining area of northern France. Foulkes et al., (2017) applied the UBM method to measure bioaccessibility of $\mathrm{Pb}$, Th, and $\mathrm{U}$ on solid wastes and soils from an abandoned uranium mine site in South West England. However, in Italy there is little to no attention towards inclusion of oral bioaccessibility in studies reporting HHRA (Kumpiene et al., 2017). Consequently, the present study provides evidence towards evaluating bioaccessibility to support the HHRA procedures for two abandoned mine sites in Italy.

Potentially toxic elements (PTE) are associated with the various components in soils and the mineral phases of solid wastes in different ways, and these associations can lead to variation in both mobility and availability (Cipullo et al., 2018). A wide range of soil properties can thus lead to variation in bioaccessibility of PTE such as mineralogy, soil $\mathrm{pH}$, organic matter content, presence of clay, iron oxides alumino-silicates in matrix as reported in other studies (Ruby et al., 1999; Peijenenburg and Jager, 2003; Martin and Ruby, 2004; Basta et al., 2005; Palumbo-Roe and Klinck, 2007; Denys et al., 2009; Reis et al., 2014; Palumbo-Roe et al. 2015). Therefore, in order to assess bioaccessibility of PTE, it becomes imperative to study geochemical data and encapsulation of PTE in mineral phases.

Considering the challenges linked with evaluating bioaccessibility and understanding factors influencing bioaccessibility, the present study focuses on extractive waste (EW) and soils from the abandoned mine site at Campello Monti, which was important for Ni exploitation from mafic formations in north-west Italy. Specifically in this study, the total concentration, bioaccessible fraction and the distribution of PTE were determined using non-specific sequential extraction and chemometric analysis along with mineralogical analysis of the extractive waste and soil samples.

\section{Methodology}

\subsection{Site description}


Campello Monti is a small settlement of Valstrona village in the northern sector of Piemonte, Italy. Geologically, the site (Figure 1) is present in the ultramafic layers of mafic complex of Ivrea Verbano Zone. Ivera- Verbano zone is a tectonic unit which has preserved the transition from amphibolite to granulite facies (Redler et al.,2012). The mafic formation consists of a sequence of cumulate peridotites, pyroxenites, gabbros and anorthosites, together with a large, relatively homogeneous body of gabbro-norite, grading upwards into gabbro-diorite and diorite. Campello Monti area consists of lherzolites, in places with titanolivin, in large and smaller masses.

The rocks in this area are rich in nickel, copper and cobalt. The area was exploited for nickel production from $\mathrm{Fe}-\mathrm{Ni}-\mathrm{Cu}-\mathrm{Co}$ magmatic sulphide deposits occurring from the Sesia to Strona valleys from 19th Century (1865) until 1940s. The ore was extracted using underground mining activities which left waste rocks near the mine tunnels (Mehta et al., 2018).

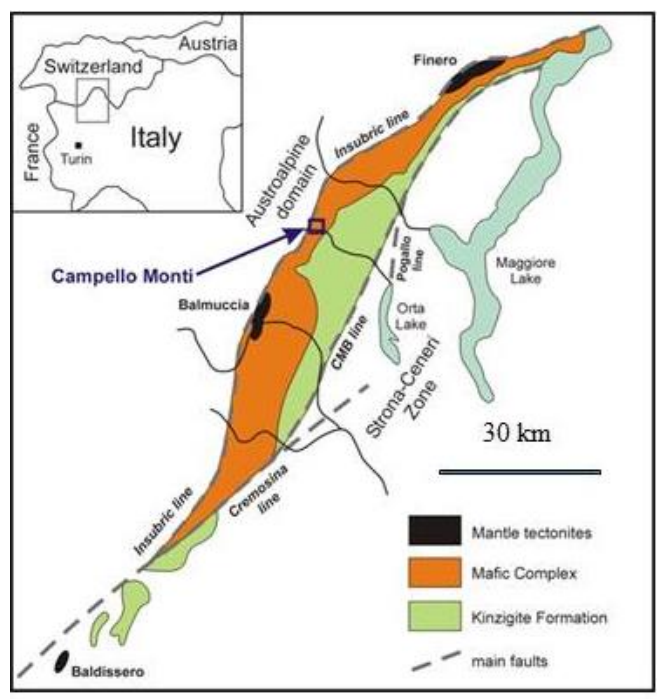

Figure 1. Geological setting of Campello Monti (modified from Fiorentini and Beresford, 2008).

\subsection{Sample collection and preparation}

Site investigation was performed to collect information about waste typology and location, in order to ensure that the facilities are suitable for characterisation and sampling. The sampling site at Campello Monti is composed of different waste rock dumps. These waste rock dumps were placed on the north of the Strona stream and were formed by the dumping in vertical sequence of non- 
valuable mineralisations and non-mineralised rocks. A systematic sampling strategy was adopted in order to obtain representative data of the whole waste facility. Waste rock material was sampled using hand shovel and a hammer (where necessary). In total 26 samples of waste rock were collected at the site in July 2016 (Error! Reference source not found.). Each sample (8-10 kg) was collected in an area of $1.5 \mathrm{~m}^{2}$, after removing organic residues. Additionally, a total of 9 soil samples were taken near the waste rock dumps to the north and south of the Strona stream during the sampling campaigns in June 2016 and March 2017. In order to obtain representative soil samples, the samples taken were formed by mixing 4 subsamples taken at the vertices of a $1 \mathrm{~m} \times 1 \mathrm{~m}$ square. All samples were taken at depth of 0-15 cm. The extractive waste samples and soil samples were dried in an oven for a period of $24 \mathrm{~h}$ to remove any moisture. Samples were then sieved through $2 \mathrm{~mm}$ sieves and quartered to obtain a representative sample size of $10 \mathrm{~g}$. The $\mathrm{pH}$ was measured in a 1: 2.5 suspension of each sample in water (ISO 10390, 2005).

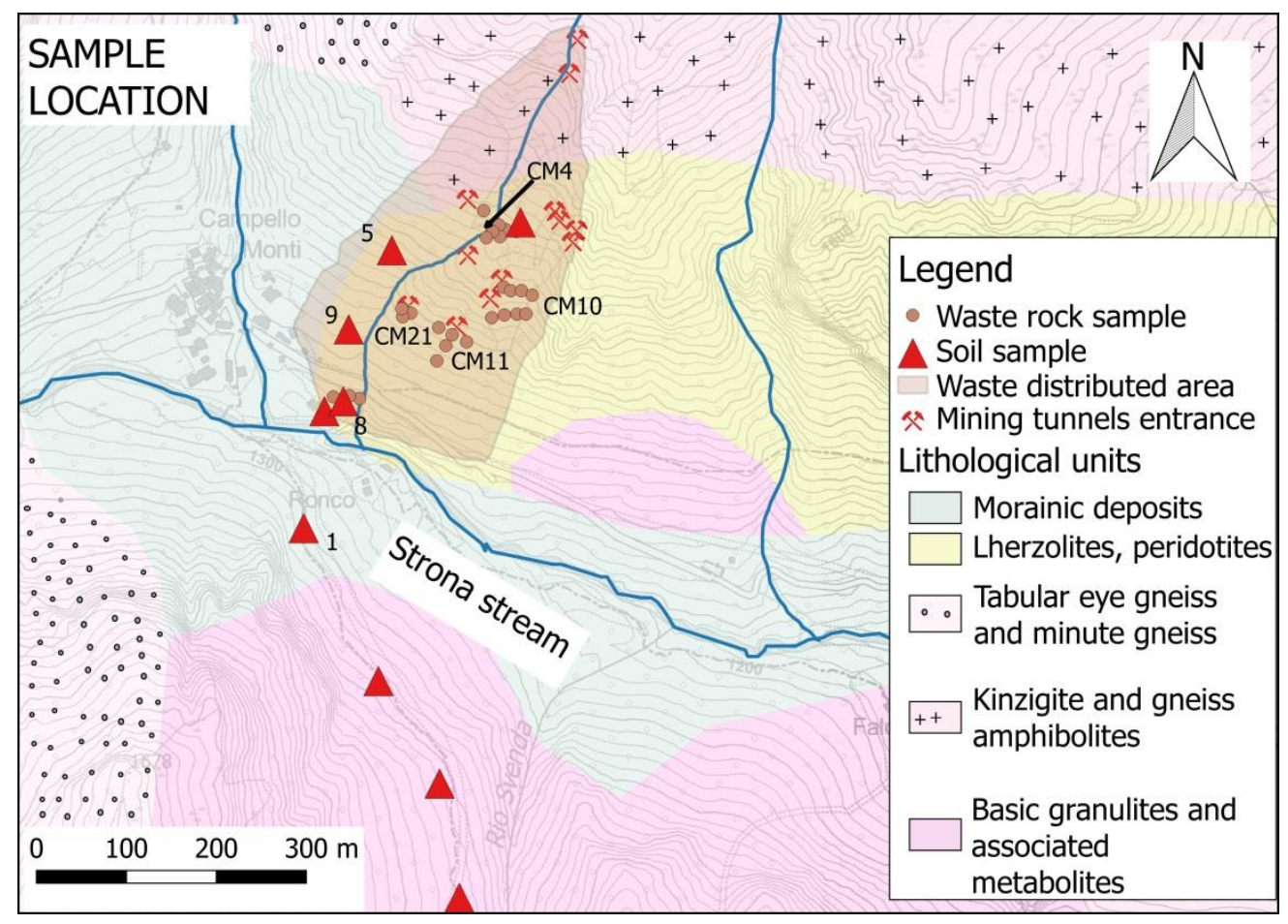

Figure 2. Waste rock and soil sample locations at Campello Monti. Sample numbers are shown for the samples analyzed for bioaccessibility.

\subsection{Total concentrations measurement}


The samples were analyzed for their concentrations of chemical elements on the $2 \mathrm{~mm}$ fraction using the method described in U.S. EPA, 3051 A, (2007) and U.S. EPA, 6010 C, (2007). Briefly, $0.5 \mathrm{~g}$ of sample was digested using $3 \mathrm{ml}$ concentrated $\mathrm{HNO}_{3}$ and concentrated $\mathrm{HCl}(1: 3)$. The concentrations of $\mathrm{As}, \mathrm{Be}, \mathrm{Cd}, \mathrm{Co}, \mathrm{Cr}$ (total), $\mathrm{Cu}, \mathrm{Ni}, \mathrm{Pb}, \mathrm{Sb}, \mathrm{Se}, \mathrm{V}$ and $\mathrm{Zn}$ were measured using an Ametek Spectro Genesis Inductively Coupled Plasma-Optical Emission Spectrometer (ICP-OES). The instrument was provided with an Ametek monochromator, a cyclonic spray chamber and a Teflon Mira Mist nebulizer. The instrumental conditions included a plasma power of $1.3 \mathrm{~kW}$, sample aspiration rate of $30 \mathrm{rpm}$, argon nebulizer flow of $11 / \mathrm{min}$, argon auxiliary flow of $11 / \mathrm{min}$ and argon plasma flow of 12 1/min. All the reagents used were of analytical grade. All metal solutions were prepared from concentrated stock solutions (Sigma Aldrich). High-purity water (HPW) produced with a Millipore Milli-Q Academic system was used throughout the analytical process. All samples were analyzed in duplicate.

\subsection{Bioaccessibility analysis (Unified BARGE method)}

Following the analysis on total concentration of elements for the fraction under $2 \mathrm{~mm}$, samples were selected for measurement of bioaccessible concentrations. Waste rock samples and soil samples were selected to ensure representation of each dump and lithology in the final selected samples. For tailings, the two samples closest to the ground surface were measured for bioaccessible concentrations. The total metal concentrations were measured on $(<250 \mu \mathrm{m}$ fraction of these samples) using aqua regia extractions as described in section 2.3. Following the analysis on total concentration of PTE on the $<2 \mathrm{~mm}$ fraction, samples of waste rock, soil and tailings were selected for measurement of bioaccessible concentrations, ensuring good representation of each matrix. For tailings, the two samples at the nearest depth from the ground were measured for bioaccessible concentrations. Each sample was sieved to $<250 \mu \mathrm{m}$ and total concentrations of PTE were measured using aqua regia extractions as explained in section 2.3. The Unified BARGE method (UBM) was also followed for measuring bioaccessible concentrations on the $<250 \mu \mathrm{m}$ fraction (BARGE 2010, 
Denys et al., 2012). To ensure quality control of the extraction process each batch of UBM extractions $(n=10)$ included one procedural blank, six unknowns, one duplicate of two unknown samples and one soil reference material (BGS102) (BARGE 2010; Hamilton et al., 2015). Table 1 shows the comparison of the certified and measured values of the BGS 102 extractions. As pH plays an important role in controlling the leaching of the PTE from the matrix and overall extraction process, the $\mathrm{pH}$ meter was calibrated before extraction of every batch of samples.

Unified BARGE method extractions were carried out using simulated digestive fluids including saliva, gastric fluid, bile and duodenal fluid, which were prepared from inorganic and organic reagents and enzymes one day prior to sample extractions. These fluids were used to represent three main compartments of human digestive system: mouth, stomach and small intestine. The extraction consists of two phases, gastric and gastro-intestinal for which $0.4 \pm 0.0005 \mathrm{~g}$ of sample was weighed in replicate in polycarbonate tubes (1 replicate for the gastric phase and 1 replicate for the gastro-intestinal phase). For gastric phase extractions, saliva and gastric fluids were added to each tube ( $\mathrm{pH}$ adjusted to $1.2 \pm 0.05$ ), followed by $1 \mathrm{~h}$ of end-over-end rotation. The rotator was placed in oven at constant temperature of $37^{\circ} \mathrm{C}$. One of the replicates was extracted through centrifugation at $4500 \mathrm{~g}$ for $15 \mathrm{~min}$ ( $\mathrm{G}$ phase), while the second replicate was retained for gastro-intestinal phase (GI phase) extraction. Simulated duodenal and bile fluids were added to this tube ( $\mathrm{pH}$ adjusted to $6.3 \pm 0.5$ ) and rotated end-over-end for 4 hours at $37^{\circ} \mathrm{C}$. This was followed by an identical centrifugation procedure to obtain GI phase extracts. For both extractions, $10 \mathrm{ml}$ of the supernatant was collected and preserved with $0.2 \mathrm{ml}$ concentrated $(15.9 \mathrm{M}) \mathrm{HNO}_{3}$. Determination of PTE was performed by ICP-MS (Perkin-Elmer NexION 350X), while using internal standard (Rh). The bioaccessible fraction (BAF) for both the phases was calculated using Equation 1. To apply a conservative approach for human health risk assessment, BAF is reported as the percentage of highest bioaccessible concentration from gastric or gastro-intestinal phase. 
$\mathrm{BAF}=\frac{\text { Concentration of bioaccessible element }\left(\frac{\mathrm{mg}}{\mathrm{kg}}\right)}{\text { Total concentration of element }\left(\frac{\mathrm{mg}}{\mathrm{kg}}\right)} \times 100$

\subsection{Chemometric identification of substrates and element distribution (CISED)}

A non-specific sequential nitric acid extraction (Cave et al., 2004) was carried out on selected samples $(\mathrm{n}=5)(\mathrm{n}=2$ waste rocks, $\mathrm{n}=3$ soil). Briefly, $2 \mathrm{~g}$ of sample was sequentially extracted with

$10 \mathrm{ml}$ of deionized water and solution of increasing concentration of $\mathrm{HNO}_{3}$ ranging from $0.01 \mathrm{M}$ to

5.0 M. A total of 7 solutions were used twice $(0.0 \mathrm{M}, 0.01 \mathrm{M}, 0.05 \mathrm{M}, 0.1 \mathrm{M}, 0.5 \mathrm{M}, 1.0 \mathrm{M}$ and 5.0

M), with progressive addition of $\mathrm{H}_{2} \mathrm{O}_{2}(0.25,0.50,0.75$, and $1 \mathrm{ml})$ in the last 4 extracting solutions

to facilitate the precipitation of oxides. Each solution was mixed for $10 \mathrm{~min}$ in an end-over-end shaker and centrifuged (4350 g for $5 \mathrm{~min}$ ) to separate solid and liquid fractions. The solid fraction was then resuspended in the following extracting solution. The recovered liquid fraction was filtered with a $0.45 \mu \mathrm{m} 25 \mathrm{~mm}$ nylon syringe filterand diluted 4 times with deionized water prior to analysis. Extracts were spiked with internal standards ( $\mathrm{Sc}, \mathrm{Ge}, \mathrm{Rh}$, and $\mathrm{Bi}$ ) and the following elements $\mathrm{Ca}, \mathrm{Fe}, \mathrm{K}, \mathrm{Mg}, \mathrm{Mn}, \mathrm{Na}, \mathrm{S}, \mathrm{Si}, \mathrm{P}, \mathrm{Al}, \mathrm{As}, \mathrm{Ba}, \mathrm{Cd}, \mathrm{Co}, \mathrm{Cr}, \mathrm{Cu}, \mathrm{Hg}, \mathrm{Li}, \mathrm{Mo}, \mathrm{Ni}, \mathrm{Pb}, \mathrm{Sb}, \mathrm{Se}$, extraction procedure.

\subsection{Modelling}

Solid phase distribution of elements in soil and waste rock was calculated with MatLab (MatLab® Version R2015a) using a self-modelling mixture resolution algorithm (SMMR) developed by Cave et al. (2004). This modelling algorithm was used to identify (1) soil components with similar physical-chemical properties, (2) chemical composition data (single elements in each soil component expressed as percentage), and (3) amount of elements in each component (expressed in $\mathrm{mg} / \mathrm{kg}$ ). The algorithm was run separately for waste rock and soil producing 7 and 8 distinct sets of 
physico-chemical phases for each of these respective runs. In order to chategorise these physiochemical phases into common distinct soil phases hierarchal clustering was used in combination with geochemical profile interpretations. Briefly, heatmaps from hierarchical clustering were produced with a mean-centered and scaled matrix of profile and composition data using the Ward's method in $\mathrm{R}$ (v.3.4.1) and the results obtained were plotted with ggplot2, reshape2, grid and ggdendro packages (Wickham,2007; Wickham, 2009; Chang et al. 2013).

\subsection{Mineralogical analysis}

The mineralogical analysis of waste rock samples was performed in a previous study (Rossetti et al., 2017). Consequently, only the soil sample was analyzed for mineral phases in present study. Micro-X-ray fluorescence (micro-XRF) was used to identify crystalline phases in the bulk soil sample (sample code - 8). Element X-ray maps of soil sample were acquired using a micro-XRF Eagle III-XPL spectrometer equipped with an EDS Si(Li) detector and with an EdaxVision32 micro-analytical system. The operating conditions were $2.5 \mu$ s counting time, $10 \mathrm{kV}$ accelerating voltage and a probe current of $20 \mu \mathrm{A}$. The spatial resolution was about $65 \mathrm{~mm}$ in both $\mathrm{x}$ and $\mathrm{y}$ directions. The elemental maps were processed to determine mineral phases in soil using software program Petromod (Cossio et al., 2002). The micromorphology and associated chemical analysis of solid phases in soil were analyzed with a Cambridge Stereoscan 360 scanning electron microscope (SEM) equipped with an energy-dispersive spectrometry (EDS) Energy 200 system and a Pentafet detector (Oxford Instruments). $10 \mathrm{kV}$ accelerating voltage and $50 \mathrm{~s}$ counting time were used for analysis of the minerals. SEM-EDS quantitative data (spot size $2 \mu \mathrm{m}$ ) were acquired and processed using the Microanalysis Suite Issue 12, INCA Suite version 4.01; natural mineral standards were used to calibrate the raw data; the $\varphi \rho Z$ correction (Pouchou \& Pichoir, 1988) was applied. Absolute error is $1 \delta$ for all calculated oxides.

\section{Results}




\subsection{Total concentrations of PTE}

215 The $\mathrm{pH}$ and total concentrations of PTE in waste rock samples (no. of samples, $\mathrm{n}=26$ ) and soil samples (no. of samples, $\mathrm{n}=9$ ) are summarized in Figure 3. The value of $\mathrm{pH}$ varied from 5.0 to 7.1 with mean value of 5.9. The results showed that concentrations of Ni varied from $15.2 \mathrm{mg} / \mathrm{kg}$ to $2294 \mathrm{mg} / \mathrm{kg}$ with an average concentration of $640 \mathrm{mg} / \mathrm{kg}$. The presence of slightly acidic samples and high concentrations of $\mathrm{Ni}$ can be attributed to the presence of ultramafic lithology rich in olivine and pyroxene in Campello Monti. The concentration of $\mathrm{Cr}$ varied from $39 \mathrm{mg} / \mathrm{kg}$ to 620 $\mathrm{mg} / \mathrm{kg}$ with an average concentration of $299 \mathrm{mg} / \mathrm{kg}$, while concentrations of Co ranged from 2.4 $\mathrm{mg} / \mathrm{kg}$ to $77.8 \mathrm{mg} / \mathrm{kg}$ with a mean concentration of $32.1 \mathrm{mg} / \mathrm{kg}$. The presence of $\mathrm{Cr}$ and Co is due to the fact that $\mathrm{Ni}$ in earth's crust exhibits chalcophile and lithophile characteristics and is found to be associated with $\mathrm{Cr}$ and Co. Copper was found to vary from $19 \mathrm{mg} / \mathrm{kg}$ to $806 \mathrm{mg} / \mathrm{kg}$ with mean concentration of $284 \mathrm{mg} / \mathrm{kg}$. The presence of $\mathrm{Cu}$ suggests sulphide rich minerals (e.g. pyrite and chalcopyrite) that host both $\mathrm{Ni}$ and $\mathrm{Cu}$, may be present at the site. It should be noted that concentrations of $(\mathrm{Ni}, \mathrm{Cr}, \mathrm{Co}$ and $\mathrm{Cu}$ in waste rocks are higher than Italian permissible limits for soils for recreational and habitation areas (Ministero dell'ambiente e della tutela del territorio, 2006, decree no. 152/06). Analysis on soil samples showed that $\mathrm{pH}$ values ranged from 5.7 to 7.6 with average value of 7.0. The samples were found to be in near neutral conditions and less acidic than waste rocks samples. Total $\mathrm{Ni}, \mathrm{Cr}$ and $\mathrm{Cu}$ ranged from 212 to $594 \mathrm{mg} / \mathrm{kg}, 46$ to $795 \mathrm{mg} / \mathrm{kg}$ and 66 to $345 \mathrm{mg} / \mathrm{kg}$ respectively. Mean $\mathrm{Ni}, \mathrm{Cr}$, Cu concentrations, were 347, 296 and $200 \mathrm{mg} / \mathrm{kg}$, an order of magnitude above the Italian permissible limits for soils for recreational and habitation areas. Concentrations of $\mathrm{V}$ were found to vary from $38 \mathrm{mg} / \mathrm{kg}$ to $126 \mathrm{mg} / \mathrm{kg}$ with a mean concentration of $72 \mathrm{mg} / \mathrm{kg}$. Concentrations of other elements were found to be within permissible limits. The presence of PTE in soil can be explained on the basis of lithogenic origin of soils and possible transport of PTE from extractive waste dumps. 

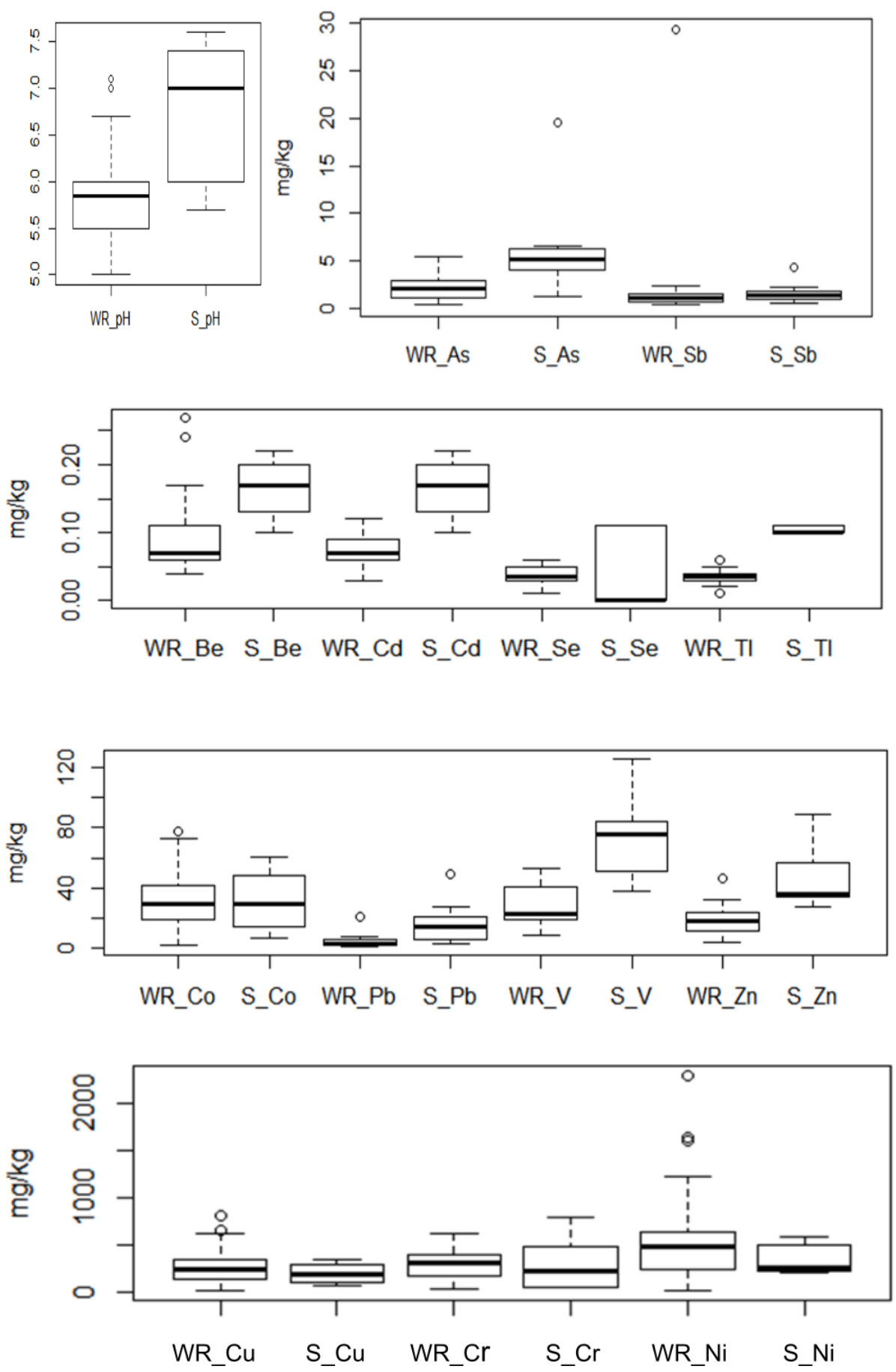

240 Figure 3. Box and Whisker plots showing $\mathrm{pH}$ and concentration of PTE in $\mathrm{mg} / \mathrm{kg}$ in waste rock $241(\mathrm{n}=26)$ and soil samples $(\mathrm{n}=9)$ on $<2 \mathrm{~mm}$ size fractions at Campello Monti. $\mathrm{pH}$ and elements on $\mathrm{X}$ 242 axis are provided with sample identification code WR for waste rocks and S for soil samples.

\subsection{Bioaccessible concentrations}

245 The total and bioaccessible concentrations of $\mathrm{As}, \mathrm{Cd}, \mathrm{Co}, \mathrm{Cr}, \mathrm{Cu}, \mathrm{Ni}, \mathrm{Pb}$ and $\mathrm{V}$ in waste rock and 246 soil samples at Campello Monti are presented in Table 2. Total concentrations for the $<250 \mu \mathrm{m}$ size 
fraction were considerably higher than total concentrations for size fractions under $2 \mathrm{~mm}$ (reported in Figure 3) potentially due to an increase in surface area and thus higher the absorption of PTE to particles (Yao et al., 2015). The bioaccessible concentrations were measured both for gastrointestinal and gastric phases. It was observed that for all PTE except As, metals were more bioaccessible in the gastric phase than the gastrointestinal phase. Bioaccessible fraction (BAF) was calculated as the ratio of the higher value of bioaccessible concentration (either gastric or gastrointestinal) to total concentration. The highest bioaccessibility value is used to ensure conservative values are used during risk assessment.

Total concentrations of As in waste rock and soil samples varied from 5.6 to $11.1 \mathrm{mg} / \mathrm{kg}$ and from 8.8 to $39.3 \mathrm{mg} / \mathrm{kg}$ respectively. The bioaccessible concentrations in gastrointestinal phase in waste rock and soil samples varied from 0.6 to $1 \mathrm{mg} / \mathrm{kg}$ and from 1.8 to $2.7 \mathrm{mg} / \mathrm{kg}$ respectively. Mean values of BAF were found to be $10.5 \%$ for waste rock samples and $12.8 \%$ for soil samples. Waste rock and soil samples showed mean total concentrations of $\mathrm{Cd}$ as $1.3 \mathrm{mg} / \mathrm{kg}$ and $0.5 \mathrm{mg} / \mathrm{kg}$. The bioaccessible fraction were found to be varying from $3 \%$ to $19 \%$ and from $20 \%$ to $85 \%$, for waste rocks and soil, respectively.

Total concentrations of Co in waste rock and soil samples varied from 165 to $266 \mathrm{mg} / \mathrm{kg}$ and from 45 to $175 \mathrm{mg} / \mathrm{kg}$ respectively. The bioaccessible concentrations in waste rock and soil samples varied from 27 to $72 \mathrm{mg} / \mathrm{kg}$ and from 5 to $53 \mathrm{mg} / \mathrm{kg}$ respectively. Mean values of BAF were found to be $20 \%$ for waste rock samples and $26 \%$ for soil samples. The results on Co bioaccessibility showed that although total concentrations of Co were very less in comparison to $\mathrm{Cr}$, the bioaccessible concentrations were present in the same range as $\mathrm{Cr}$ due to higher bioaccessible fractions of Co in comparison to $\mathrm{Cr}$. Chromium in waste rock and soil samples was found to vary from 931 to $1569 \mathrm{mg} / \mathrm{kg}$ and from 79 to $1643 \mathrm{mg} / \mathrm{kg}$ respectively. Mean values of BAF of $\mathrm{Cr}$ for waste rock and soil samples was $1 \%$ and $2.75 \%$ respectively.

Total concentrations of $\mathrm{Cu}$ in waste rock and soil samples ranged from 953 to 2,006 mg/kg and from 85 to $848 \mathrm{mg} / \mathrm{kg}$ respectively. The bioaccessible concentrations in waste rock and soil 
samples varied from 129 to $921 \mathrm{mg} / \mathrm{kg}$ and from 27 to $222 \mathrm{mg} / \mathrm{kg}$ respectively. Mean values of BAF were found to be $31 \%$ for waste rock samples and $26 \%$ for soil samples. Copper results showed higher bioaccessibility for soil samples compared to waste rocks, indicating a contrasting behavior with respect to the other PTE analyzed. The results on $\mathrm{Cu}$ bioaccessibility showed that although total concentrations of $\mathrm{Cu}$ were not as high as $\mathrm{Ni}$, the bioaccessible concentrations were almost of the same magnitude as nickel. This can be attributed to the higher BAF values of $\mathrm{Cu}$ when compared with $\mathrm{Ni}$.

The samples were found to have very high total concentration of $\mathrm{Ni}$ in waste rock samples with variation from 1181 to $7408 \mathrm{mg} / \mathrm{kg}$. However, the bioaccessible concentrations of $\mathrm{Ni}$ in gastric phase for waste rock samples was relatively low. The bioaccessible concentrations for gastric phase for $\mathrm{Ni}$ varied from 119 to $776 \mathrm{mg} / \mathrm{kg}$ for waste rock samples, thus leading to a BAF (ratio of bioaccessible concentration to total concentration) of about $10 \%$. A similar observation was made for soil samples. The total concentration and bioaccessible concentration for soil samples ranged from $59 \mathrm{mg} / \mathrm{kg}$ to $1504 \mathrm{mg} / \mathrm{kg}$ and from 12 to $280 \mathrm{mg} / \mathrm{kg}$, respectively. Thus leading to BAFs varying from $5 \%$ to $20 \%$.

Mean values of total concentration of $\mathrm{Pb}$ in waste rock and soil samples were found to be 25 $\mathrm{mg} / \mathrm{kg}$ and $18 \mathrm{mg} / \mathrm{kg}$ respectively. The bioaccessible fraction of $\mathrm{Pb}$ in waste rock and soil samples varied from $42 \%$ to $61 \%$. Vanadium was found to vary from $34 \mathrm{mg} / \mathrm{kg}$ to $87 \mathrm{mg} / \mathrm{kg}$ for waste rock samples, with mean BAF of $4 \%$. The soil samples recorded mean values of total concentrations and bioaccessible concentrations as $106 \mathrm{mg} / \mathrm{kg}$ and $7 \mathrm{mg} / \mathrm{kg}$ respectively.

The range of bioaccessibility values reported for the soils were found to be comparable to those reported elsewhere, eg. Barsby et al. (2012) conducted bioaccessibility analysis in ultramafic geological setting of Northern Ireland using UBM and reported mean values of gastric phase of $\mathrm{BAF}$ of $\mathrm{As}, \mathrm{Co}, \mathrm{Cr}$ for soils as $14 \%, 18 \%$ and $1 \%$ respectively (here $13 \%, 26 \%$ and $3 \%$ respectively). The same study reported mean value of $\mathrm{BAF}$ for $\mathrm{Cu}$ as $31 \%$ (here $31 \%$ ), $\mathrm{Ni}$ as $12 \%$ (here $13 \%$ ), $\mathrm{V}$ as $9 \%$ (here $7 \%$ ). There was a marked difference in reported values of mean of BAF 
299 of $\mathrm{Pb}$ as reported by Barsby et al. (2012) 33\% (here 54\%). However, the value was found to be 300 more comparable with smelter contaminated agricultural soil of northern France, which showed 301 BAF of 58\% (here 54\%) (Pelfrêne et al., 2012).

302 
Table 1. Results of the UBM digests of certified reference material BGS $102(n=3)$.

\begin{tabular}{|c|c|c|c|c|c|c|c|c|c|}
\hline & & As & $\mathrm{Cd}$ & Co & $\mathrm{Cr}$ & $\mathrm{Cu}$ & $\mathrm{Ni}$ & $\mathrm{Pb}$ & $\mathrm{V}$ \\
\hline \multirow{2}{*}{ Gastric phase } & Measured & $3.17 \pm 0.13$ & $\mathrm{BDL}^{\mathrm{b}}$ & $9.57 \pm 0.61$ & $35.76 \pm 0.58$ & $8.66 \pm 0.69$ & $12.70 \pm 0.51$ & $15.35 \pm 1.16$ & $6.67 \pm 0.40$ \\
\hline & Reported $^{\mathrm{a}}$ & 3.90 & 0.02 & 9.50 & 36.70 & 8.60 & 13.00 & 15.30 & 6.10 \\
\hline \multirow{2}{*}{$\begin{array}{l}\text { Gastro-intestinal } \\
\text { phase }\end{array}$} & Measured & $2.54 \pm 0.38$ & & $5.70 \pm 0.75$ & $6.19 \pm 1.06$ & & $9.86 \pm 0.82$ & & $2.23 \pm 0.46$ \\
\hline & Reported & 3.30 & & 5.50 & 13.10 & & 10.50 & & 3.40 \\
\hline
\end{tabular}

${ }^{\mathrm{a}}$ Hamilton et al., 2015; ${ }^{\mathrm{b}}$ BDL- Below detectable limit.

Table 2. Total concentrations (mg/kg), bioaccessible concentrations ( $\mathrm{G}$ and $\mathrm{GI})(\mathrm{mg} / \mathrm{kg}$ ) and BAF (\%) measured on $<250 \mu \mathrm{m}$ size fractions for samples at Campello Monti.

\begin{tabular}{|c|c|c|c|c|c|c|c|c|c|c|c|c|c|}
\hline & Sample & \multicolumn{3}{|c|}{ As } & \multicolumn{3}{|c|}{$\mathrm{Cd}$} & \multicolumn{3}{|c|}{$\mathrm{Co}$} & \multicolumn{3}{|c|}{$\mathrm{Cr}$} \\
\hline \multirow{5}{*}{ 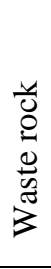 } & & GI & total & BAF & $\mathrm{G}$ & total & BAF & $\mathrm{G}$ & total & BAF & $\mathrm{G}$ & total & BAF \\
\hline & CM4 & 0.6 & 5.6 & 11 & 0.1 & 0.9 & 6 & 27 & 188 & 14 & 25 & 1398 & 1 \\
\hline & CM10 & 1 & 11.1 & 9 & 0.3 & 1.4 & 19 & 69 & 266 & 26 & 20 & 1569 & 1 \\
\hline & CM11 & 0.6 & 7.5 & 9 & 0.2 & 1.9 & 13 & 58 & 295 & 20 & 26 & 1296 & 1 \\
\hline & CM21 & 0.7 & 6.3 & 13 & 0.0 & 1.1 & 3 & 30 & 165 & 18 & 9 & 931 & 1 \\
\hline \multirow{4}{*}{ 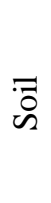 } & 5 & 1.8 & 15.3 & 11 & 0.2 & 1.0 & 20 & 53 & 175 & 31 & 54 & 1643 & 1 \\
\hline & 1 & 2.9 & 39.6 & 7 & 0.6 & 0.7 & 85 & 23 & 68 & 34 & 3 & 79 & 3 \\
\hline & 8 & 1.8 & 8.8 & 22 & 0.1 & 0.2 & 47 & 37 & 142 & 26 & 85 & 623 & 1 \\
\hline & 9 & 1.2 & 9.4 & 12 & 0.2 & 0.2 & 73 & 5 & 45 & 10 & 124 & 701 & 6 \\
\hline & & \multicolumn{3}{|c|}{$\mathrm{Cu}$} & \multicolumn{3}{|c|}{$\mathrm{Ni}$} & \multicolumn{3}{|c|}{$\mathrm{Pb}$} & \multicolumn{3}{|c|}{$\mathrm{V}$} \\
\hline \multirow{5}{*}{ 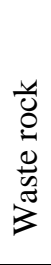 } & & $\mathrm{G}$ & total & BAF & G & total & BAF & G & total & BAF & $\mathrm{G}$ & total & BAF \\
\hline & CM4 & 129 & 953 & 14 & 119 & 1181 & 10 & 10 & 21 & 49 & 2 & 87 & 2 \\
\hline & CM10 & 754 & 1955 & 39 & 502 & 4586 & 11 & 12 & 24 & 50 & 2 & 64 & 3 \\
\hline & CM11 & 921 & 2006 & 47 & 776 & 7408 & 10 & 10 & 25 & 42 & 2 & 34 & 6 \\
\hline & CM21 & 320 & 1367 & 23 & 256 & 2864 & 9 & 14 & 28 & 50 & 2 & 61 & 3 \\
\hline \multirow{4}{*}{$\begin{array}{l}\bar{\sigma} \\
\mathscr{S}\end{array}$} & 5 & 222 & 848 & 26 & 280 & 1504 & 19 & 8 & 15 & 51 & 9 & 149 & 5 \\
\hline & 1 & 27 & 85 & 32 & 12 & 59 & 21 & 29 & 49 & 59 & 5 & 94 & 6 \\
\hline & 8 & 135 & 441 & 31 & 73 & 1455 & 5 & 2 & 4 & 44 & 3 & 79 & 4 \\
\hline & 9 & 45 & 256 & 17 & 38 & 763 & 5 & 2 & 4 & 61 & 12 & 101 & 12 \\
\hline
\end{tabular}



represented as BAF. 


\subsection{Interpretation of sequential extraction data}

Identified physico-chemical components for the most representative samples of waste rock (sample code - CM 10) and soil (sample code - 8) at Campello Monti are highlighted in Figure 4. For these samples, the chemometric data analysis identified 7 components in the waste rock sample and 8 components in the soil sample. Each row represents a component identified by the algorithm, where the name is composed with the elements that make up $>10 \%$ of the composition. The columns of the heatmap are based on model output showing the composition $(\%)$ on the left side, and on the right side the extraction profiles (E1-E14).

A combination of geochemistry knowledge, relative solubility of each component in the extracts, major elemental composition, profile, and clustering obtained from the heat maps were used to define 6 geochemically distinct clusters: pore-water, exchangeable, Fe oxide 1, clay related, Fe oxide 2). The heatmap and clustergram for remaining waste rock and soil samples are shown Supplementary Material (Figure 1).

Pore-water: In waste rock, the pore-water cluster was principally made up from $\mathrm{S}$ (c. 52.2\%) and $\mathrm{Mg}$ (c. 24.7\%). Other elements extracted were $\mathrm{Ca}($ c. $7.4 \%)$ and $\mathrm{Ni}$ (c. 8.8\%). The presence of nickel in the pore water component suggests mobility of $\mathrm{Ni}$ in the waste rock. The pore-water cluster of soil was predominantly composed of $\mathrm{S}(c .64 \%)$ and $\mathrm{Na}, \mathrm{Mg}, \mathrm{K}$ which were all present at $>5 \%$. These components in this cluster were extracted in water extractions and $0.01 \mathrm{M} \mathrm{HNO}_{3}(\mathrm{E} 1-$ E4). This was the most easily extracted cluster suggesting it could be associated with the residual salts from the original pore water in the soil.

Exchangeable: In waste rock, the exchangeable component consisted of $\mathrm{Cu}(c .36 \%), \mathrm{Mg}(c .17 \%)$, $\mathrm{S}(c .12 \%)$ and $\mathrm{Ca}(c .12 \%)$. It was removed by the $\mathrm{HNO}_{3}$ extracts over the range $0.01 \mathrm{M}$ to $0.05 \mathrm{M}$. The presence of a $\mathrm{Cu}$ rich component could be due to the presence of $\mathrm{Cu}$ bearing ores, such as $\mathrm{Cu}$ Fe sulphides (chalcopyrite, $\mathrm{CuFeS}_{2}$ and cubanite, $\mathrm{CuFe}_{2} \mathrm{~S}_{3}$ ) at the site. The exchangeable cluster of 
soil was principally composed of $\mathrm{Al}(c .48 \%), \mathrm{Ca}(c .27 \%), \mathrm{Cu}(c .7 \%)$ and $\mathrm{S}(c .5 \%)$. It was removed by the $\mathrm{HNO}_{3}$ extracts over the range $0.01 \mathrm{M}$ to $0.1 \mathrm{M}$. High $\mathrm{Ca}$ and $\mathrm{Al}$ concentrations combined with removal on addition of relatively weak acid suggests that this cluster was associated with the presence of K-feldspar, which was found in micro-XRF analysis of soil samples.

Clay related: This cluster was found only in soil and consisted of 4 different components extracted (Al-Si, Al-Si1, Al-Si2, Al-S). It was dominated by Al (c. 62\%) and Si (c. 34\%) and to a lesser extent by $\mathrm{Fe}($ c. 3\%). This component also consisted of highest \% of $\mathrm{Co}, \mathrm{Cr}$ and $\mathrm{Cu}$ released during CISED extractions. These components were extracted with acid concentrations from $0.01 \mathrm{M} \mathrm{HNO}_{3}$ to $1 \mathrm{M} \mathrm{HNO}_{3}$, however, the majority of elements were extracted in a narrower band of acid concentrations ranging from $0.1 \mathrm{MHNO}_{3}$ to $1 \mathrm{M} \mathrm{HNO}_{3}$ (E7-E12). The high acid strength for extraction, predominance of $\mathrm{Al}, \mathrm{Si}$ and $\mathrm{Fe}$, along with presence of trace elements in this cluster are likely to be extracted from clay related minerals and from the primary soil forming minerals such as olivine and pyroxene (Wragg 2005). Clay like minerals such as montmorillonite and kaolinite were identified during mineralogical analysis of soil sample using micro-XRF.

$\underline{\text { Fe oxide 1: }}$ The Fe oxide cluster was extracted only in waste rock. This cluster consisted of three different $\mathrm{Fe}$ dominated components (Fe-Mn-Si, Fe-Al-Cu, Fe-Mn-Al). These $\mathrm{Fe}$ dominated components were removed by acid concentrations ranging from $0.05 \mathrm{M} \mathrm{HNO}_{3}$ to $0.5 \mathrm{M} \mathrm{HNO}_{3}$ (E5E10). The important elements extracted were $\mathrm{Fe}$ (c. 39\%), $\mathrm{Al}(c .16 \%), \mathrm{Mn}(c .12 \%), \mathrm{Cu}(c .7 \%), \mathrm{Ni}$ (c. 6\%) and $\mathrm{Si}($ c. 6\%), $\mathrm{Mg}($ c. $5 \%)$. The presence of $\mathrm{Fe}, \mathrm{Cu}, \mathrm{Ni}$ rich components can be due to presence of minerals like Fe Ni sulphide (pentlandite, $(\mathrm{Fe}, \mathrm{Ni})_{9} \mathrm{~S}_{8}$ ) and $\mathrm{Cu} \mathrm{Fe}$ sulphide (chalcopyrite, $\mathrm{CuFeS}_{2}$ ), which were found in mineralogy analysis of waste rocks from this site (Rossetti et al., 2017). The presence of $\mathrm{Al}$ and $\mathrm{Si}$ in this Fe oxide cluster showed that in waste rock, both these elements are more closely associated with iron unlike the soil sample, where $\mathrm{Al}$ was extracted in clay related cluster. 
363 Fe oxide 2: In the waste rock sample, the Fe oxide cluster was principally composed of Fe (c. $65 \%)$.

364 Other elements extracted were $\mathrm{Al}, \mathrm{Mg}, \mathrm{Ni}, \mathrm{Si}, \mathrm{S}$ with varying concentration from $2.6 \%$ to $12 \%$. It

was removed by the $\mathrm{HNO}_{3}$ extracts over the range $0.5 \mathrm{M}$ to $5 \mathrm{M}$ (E9-E14). The presence of Fe,S

rich components could be due to presence of Fe sulphide mineral (pyrrhotite, $\mathrm{Fe}_{(1-\mathrm{x})} \mathrm{S}$ ) observed in

microscopic images of waste rock from this site (Rossetti et al., 2017). The dominance of Fe and

high acid extracts required to extract these components could be due to presence of hematite

occurring naturally in the site (Rossetti et al., 2017). The presence of two different Fe containing

components for waste rock suggests the presence of different Fe oxide forms such as amorphous

soil included $\mathrm{Fe}(c .75 \%), \mathrm{Al}(c .11 \%), \mathrm{Mg}(c .6 \%)$ and was removed by extracts containing $\mathrm{HNO}_{3}$

$\mathrm{Cr}$ and $\mathrm{Ni}$.

Clay related (4)

Pore-water (1)

Fe oxide 1 (3)

Exchangeable (2)

Fe oxide 2 (5)

Figure 4. Heatmap and clustergram for CISED extracted waste rock and soil samples of Campello Monti (CM 10, and soil sample code - 8). The dendogram on the right hand side shows how components link together. Elemental composition data is on the left-hand side separated with a dashed vertical white line from the extraction number data (E1-14) on the right. The horizontal white lines divide the map into clusters. High concentrations are depicted by white/light grey and low concentrations by dark grey/black. Component names comprise a sample identification code (WR and S) followed by the principal elements recorded for each component. 


\subsection{Mineralogical analysis}

386 Semi quantitative analysis using micro-XRF showed that the dominant minerals present in soil 387 (sample code - 8) were clay related minerals (kaolinite and montmorillonite), Fe $\mathrm{Al}(\mathrm{Mg})$ silicates, 388 olivine, plagioclase and pyroxene. The secondary minerals determined during the analysis were Fe 389 oxides, K-feldspar, Mn phases and sulphides. The results from SEM analysis (Figure 5) showed 390 that $\mathrm{As}, \mathrm{Cr}, \mathrm{Cu}$ and $\mathrm{Ni}$ were locked within mineral grains. Arsenic was present in the minerals that 391 did not contain Al. One of the reason could be that in primary rock forming silicate minerals, As 392 can be incorporated in minerals through replacement of Al. It was also observed that As was found 393 to be occurring in the mineral phases rich in Fe-Mg, showing strong association of As with Fe-Mg 394 in the soil. This was also recorded in CISED analysis of soil sample where As was extracted in very 395 high percentage in $\mathrm{Fe}-\mathrm{Mg}$ component. Chromium, $\mathrm{Cu}$ and $\mathrm{Ni}$ were found to be associated with both $396 \mathrm{Al}$ rich and $\mathrm{Fe}-\mathrm{Mg}$ silicate minerals. 

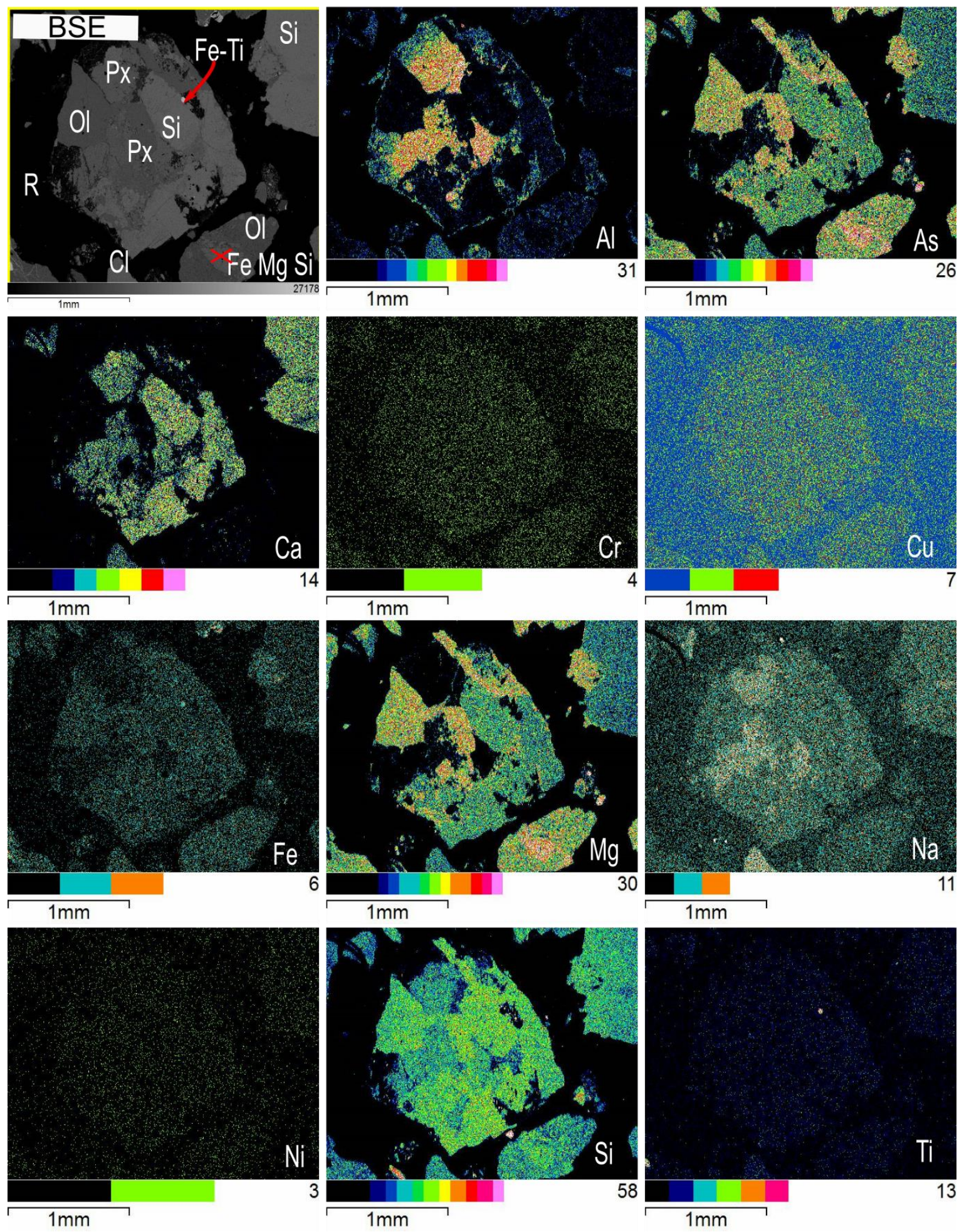

399 Figure 5. Detail of elemental distribution and composition of soil (sample code 8) - Back scattered 400 electron (BSE) image showing $\mathrm{Cl}$ : Clay related mineral (montmorillonite), $\mathrm{FeMgSi}: \mathrm{Fe} \mathrm{Mg}$ 401 silicates, Fe-Ti : Fe-Ti oxide, Ol : Olivine, Px : Pyroxene, R : resin, Si : Ca Mg Fe silicates and 402 corresponding X-ray maps (SEM) for $\mathrm{Al}, \mathrm{As}, \mathrm{Ca}, \mathrm{Cr}, \mathrm{Cu}, \mathrm{Fe}, \mathrm{Mg}, \mathrm{Na}, \mathrm{Ni}, \mathrm{Si}$ and $\mathrm{Ti}$. 


\subsection{Relation of mineralogy and CISED to bioaccessibility}

407

The PTE extracted and their bioaccessible fraction are plotted in Figure 6. The waste rock sample contained $11 \mathrm{mg} / \mathrm{kg}$ of As and only $1 \mathrm{mg} / \mathrm{kg}$ of this was bioaccessible. The total concentration of As extracted by CISED was also $1 \mathrm{mg} / \mathrm{kg}$, indicating that As extracted in both the methods was similar. $80 \%$ of total CISED extracted As was associated with the Fe oxide 2 cluster. The Campello Monti site is rich in Fe bearing minerals suggesting that dissolution of Fe oxides/oxyhydroxides took place leading to As in extracted solutions. $9 \mathrm{mg} / \mathrm{kg}$ of As was present in the soil sample, while $1.8 \mathrm{mg} / \mathrm{kg}$ of this was bioaccessible and $1.2 \mathrm{mg} / \mathrm{kg}$ was extracted by CISED, suggesting that As could be present in mineral phases which were not dissolved through CISED but were present in the gastrointestinal phase of bioaccessibility extractions. It was observed through SEM analysis that As was locked in mineral phases of soil sample. This could be due to the presence of organic reagents, body temperature conditions and/or the longer reaction time for UBM solutions. In fact, Yunmei et al. (2004) found that during dissolution of Fe-As-S rich mineral assemblages the concentration of As in solution tends to increase with increase in temperature and time.

The total concentration of $\mathrm{Cu}$ in waste rock was $1955 \mathrm{mg} / \mathrm{kg}$ while only $650 \mathrm{mg} / \mathrm{kg}$ of $\mathrm{Cu}$ (35\%) was extracted by CISED extractions. Similar observations were made for $\mathrm{Cu}$ present in soil where $33 \%$ of $\mathrm{Cu}$ was removed in CISED extractions with total concentration and total CISED extracted concentrations of $441 \mathrm{mg} / \mathrm{kg}$ and $135 \mathrm{mg} / \mathrm{kg}$, respectively.

The bioaccessible concentration of $\mathrm{Cu}$ in waste rock was $157 \mathrm{mg} / \mathrm{kg}$ resulting in higher bioaccessible $\mathrm{Cu}$ concentrations than $\mathrm{Cu}$ concentrations recorded during CISED extractions. It suggests that $\mathrm{Cu}$ associated with $\mathrm{Fe}$ and $\mathrm{S}$ present in Fe oxide 1 cluster, which did not get extracted in CISED extractions, was extracted in bioaccessibility experiments. However in soil the bioaccessible concentration was less than the CISED extracted concentration. Bioaccessibility of $\mathrm{Cu}$ in soil was due to exchangeable, Fe oxide 2 and dissolution of clay related clusters, while $\mathrm{Cu}$ present in the Fe oxide 2 component did not contribute to bioaccessible $\mathrm{Cu}$. The differences in 
bioaccessible $\mathrm{Cu}$ concentrations in soil and waste rock could be due to a) the presence of $\mathrm{Cu}$ in clay related minerals rich in metal silicate phases in soil. While in waste rocks $\mathrm{Cu}$ was associated with metal sulphides. It has been found that $\mathrm{Cu}$ tends to form stable and relatively inert complex with $\mathrm{Si}$ (Teien et al., 2006), leading to reduction in dissolution, b) the difference in CISED extracted ratio of concentration of $\mathrm{S} / \mathrm{Fe}$. It is worth mentioning that the ratio of total $\mathrm{S} / \mathrm{Fe}$ for CISED extracted concentration in waste rock and soil was $12.8 \%$ and $7.6 \%$ respectively. Studies on dissolution reactions of $\mathrm{Cu}$ has concluded that $\mathrm{Cu}$ is more chalcophile than siderophile and tends to dissolve faster with increase in ratio of $\mathrm{S} / \mathrm{Fe}$ in iron-sulphur based solutions (Holzheid and Lodders, 2001).

In waste rock samples it was observed that the gastric phase bioaccessible concentrations of $\mathrm{Cr}$ and $\mathrm{Ni}$ increased with increase in total concentration potentially suggesting that the majority of bioaccessible $\mathrm{Cr}$ and $\mathrm{Ni}$ is derived from phases which contribute to the total $\mathrm{Cr}$ and $\mathrm{Ni}$ in the sample (Cox et al. 2013). The total concentration of $\mathrm{Cr}$ in waste rock was $1,569 \mathrm{mg} / \mathrm{kg}$ while $51.2 \mathrm{mg} / \mathrm{kg}$ was extracted by CISED. The total concentration of $\mathrm{Ni}$ in waste rock was $4,586 \mathrm{mg} / \mathrm{kg}$, however only $661 \mathrm{mg} / \mathrm{kg}$ was removed during the CISED procedure. The extraction of $4 \%$ of total $\mathrm{Cr}$ and $14 \%$ of total $\mathrm{Ni}$ by CISED suggests that the majority of $\mathrm{Cr}$ and $\mathrm{Ni}$ was present in less reactive minerals such as olivine and pyroxenes that are resistant to attack by $\mathrm{HNO}_{3}$. Pyroxene and olivine are both known to host $\mathrm{Cr}$ and $\mathrm{Ni}$ are known to be the primary minerals at the site (Rossetti et al., 2017). The source of bioaccessible $\mathrm{Cr}$ in the waste rock with the partial dissolution of Fe oxide 2 is shown in Figure 6E. For $\mathrm{Ni}$, it was observed that the same fraction was the source of bioaccessibility, in addition to dissolution of pore-water, exchangeable and Fe oxide 1 components. Higher concentrations of $\mathrm{Ni}$ than $\mathrm{Cr}$ in pore water and exchangeable components suggests easy dissolution of $\mathrm{Ni}$. It could be because $\mathrm{Ni}$ is primarily hosted by olivine in ultramafic rocks. Dissolution of olivine has been found to be rapid in comparison to most silicate minerals as it has simpler structure (Pokrovsky and Schott, 2000). Venturelli et al. (2016) while studying weathering of ultramafic rocks, found that $\mathrm{Ni}$ tends to be more mobile than $\mathrm{Cr}$ and was found in higher concentrations in weathered rocks. Another study reporting $\mathrm{Cr}$ and $\mathrm{Ni}$ mobility concluded that $\mathrm{Ni}$ 
tends to be more readily transferred to secondary minerals (Quantin et al., 2008). Cox et al. (2017) found that $\mathrm{Cr}$ concentrations in basaltic soils were related to highly recalcitrant chrome spinel and primary iron oxides, while $\mathrm{Ni}$ was more widely dispersed within the soils including in more extractable soil fractions which led to higher BAF measurements being recorded for Ni than $\mathrm{Cr}$.

The total concentration of $\mathrm{Cr}$ in soil was $623 \mathrm{mg} / \mathrm{kg}$ with a bioaccessible $\mathrm{Cr}$ concentration of $85 \mathrm{mg} / \mathrm{kg}$. The CISED method extracted $108 \mathrm{mg} / \mathrm{kg}$ of Cr. Differences in total bioaccessible and CISED extracted concentrations suggest the non-mobile nature of $\mathrm{Cr}$ in soil. Dissolution of clay related clusters and partial dissolution of Fe oxide 2 led to the bioaccessible forms of Cr. The total concentration of $\mathrm{Ni}$ in soil was $1,455 \mathrm{mg} / \mathrm{kg}$, however only $73 \mathrm{mg} / \mathrm{kg}$ was bioaccessible in gastric phase extractions. The bioaccessible form of $\mathrm{Ni}$ was likely to come predominantly from the exchangeable and clay related clusters, and to a lesser extent by the Fe oxide 2 cluster, identified by the CISED extraction (Figure 6E). The possible reason could be that the clay related cluster consisted of weathered minerals, while Fe oxide 2 cluster belongs to recalcitrant primary mineralization at the site in form of pyrrhotite $\left(\mathrm{Fe}_{(1-\mathrm{x})} \mathrm{S}\right)$, pentlandite $\left((\mathrm{Fe}, \mathrm{Ni})_{9} \mathrm{~S}_{8}\right)$, chalcopyrite $\left(\mathrm{CuFeS}_{2}\right)$ (Rossetti et al., 2017). For As, $\mathrm{Cr}$ and Ni it was observed that the BAF was higher for soil samples compared to waste rock samples. The could be because (a) elements in ultramafic lithologies are more tightly bound in the mineral lattice of the waste rocks compared to soils, (b) waste rock samples were more acidic than soil samples, which can cause some PTE to remain immobile (Ruby et al., 1999), (c) elements with particle binding abilities may become immobilized in rocks but can be released during weathering. However, the mean value of bioaccessible fractions in soil for all PTE analyzed was less than 54\%. The possible reason could be the embedment of PTE within mineral grains of soil as observed in SEM analysis. 
A

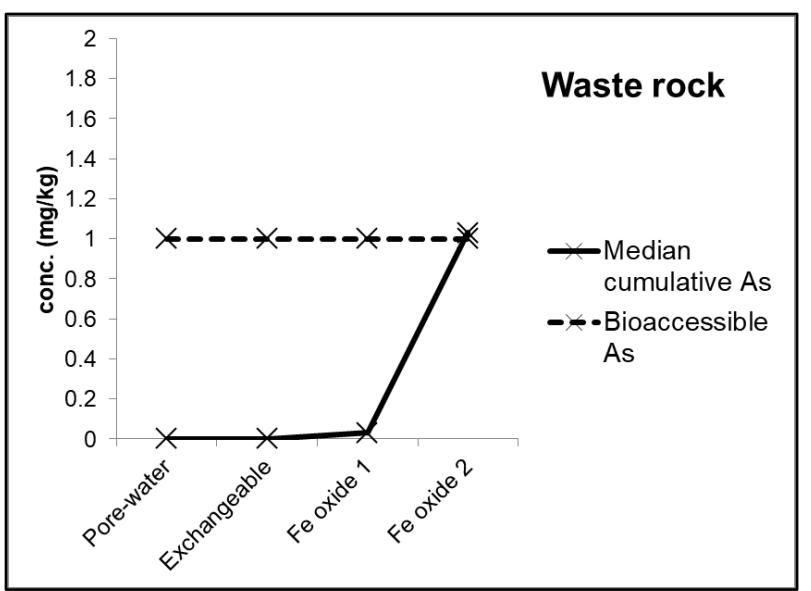

C

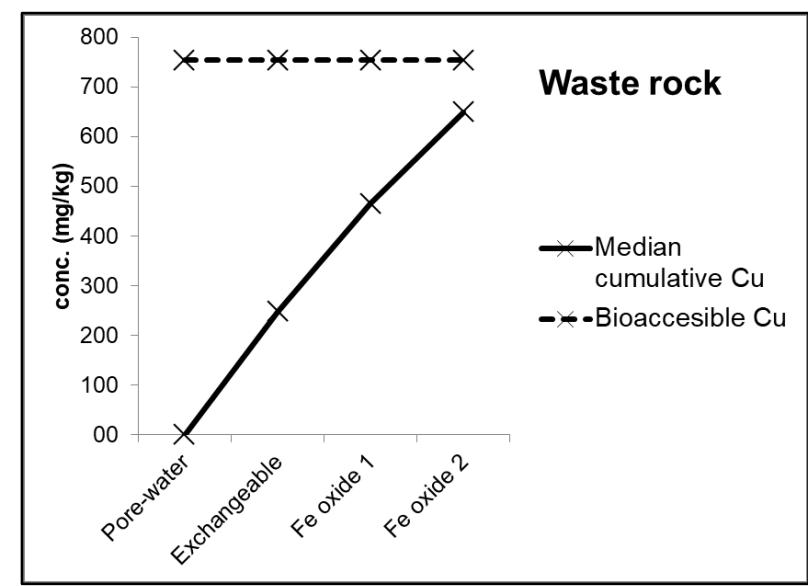

E

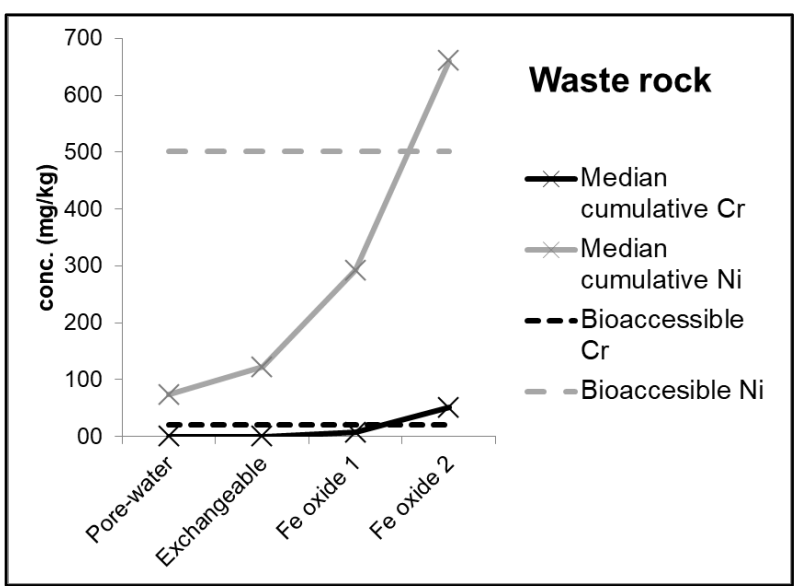

B

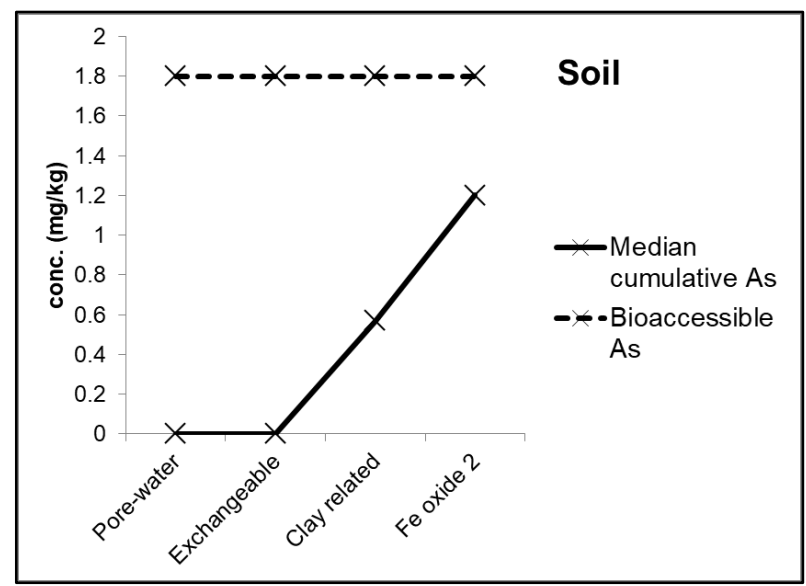

D

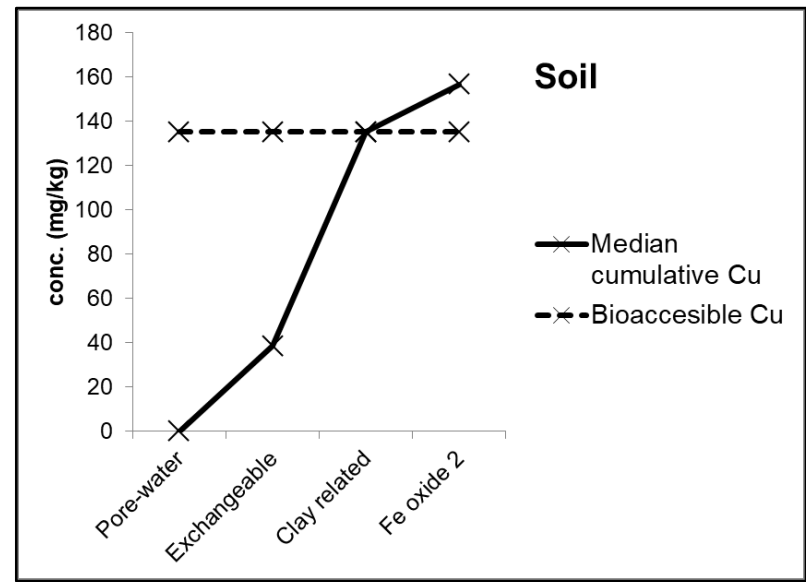

F

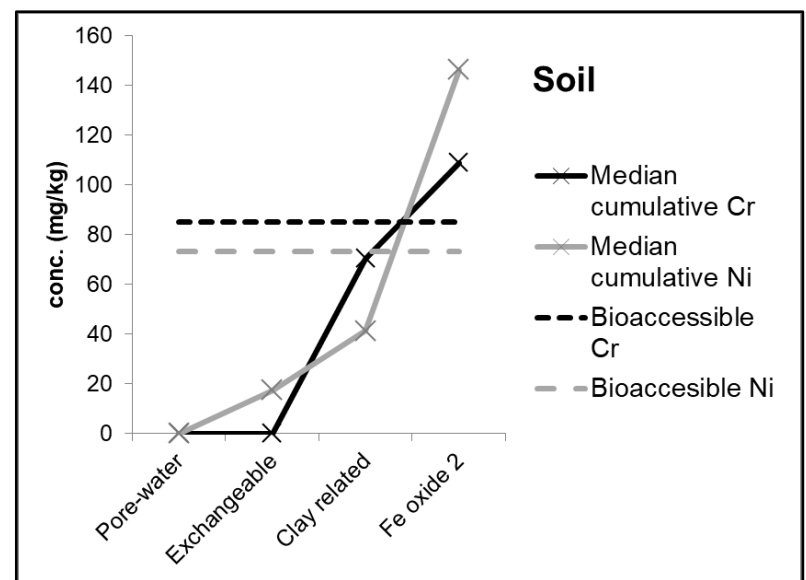

Figure 6. Median cumulative concentration of elements in different components of CISED compared with bioaccessible concentrations in samples of Campello Monti (mg/kg).

\section{Conclusions}

This study investigated total concentrations and bioaccessible concentrations of PTE at abandoned mine site of Campello Monti. Data from mineralogy analysis, non-specific sequential extraction and chemometric analysis on selected samples were also related to the oral bioaccessibility to 
understand the relationship between total concentrations, bioaccessible concentrations, the mineralogy and solid phase distribution of these elements. The extractive waste facilities and local soils around the old mining areas of Campello Monti (NW Italy) are strongly enriched in PTE. This study provided evidence that total concentrations of PTE were higher in samples with particle size $<250 \mu \mathrm{m}$ compared to samples $(<2 \mathrm{~mm})$, due to higher specific surface area in the former case. The results of total concentrations showed high concentrations of PTE. However, not all of these elements were bioaccessible. The mean value of bioaccessible fraction (ratio of bioaccessible concentration to total concentration) was observed to be significantly less than $100 \%(11 \%, 1 \%$, and $31 \%$ for $\mathrm{As}, \mathrm{Cr}, \mathrm{Cu}$ respectively in waste rocks and $31 \%, 3 \%$, and $26 \%$ for soils). The mean value of BAF of Ni was $10 \%$. Mean values of BAF of $\mathrm{V}$ in waste rock and soil were observed to be $4 \%$ and $9 \%$ respectively. It is clear that the release of PTE and potential risks to human health strongly relies on $\mathrm{pH}$, soil phases, and solubility of Fe-rich phases and presence of clay like minerals. These results show that risk assessment of the site on the basis of total concentrations of PTE alone would significantly overestimate the potential risks to human health at the site. The research conducted highlights how geological and lithological structures together with rock weathering and soil formation processes can lead to variations of bioaccessibility. Traditionally, criteria for the assessment and intervention strategies of contaminated sites have been derived using concentration-based standards and assuming that $100 \%$ of the contaminant is bioavailable. However, the results outlined in this research clearly indicate that the bioaccessibility evaluations can lead to more informed site based risk assessment.

Acknowledgements: This work was completed as part of the REMEDIATE (Improved decisionmaking in contaminated land site investigation and risk assessment) Marie-Curie Innovation Training Network. The network has received funding from the European Union's Horizon 2020 Programme for research, technological development and demonstration under grant agreement $\mathrm{n}$. 643087. REMEDIATE is coordinated by the QUESTOR Centre at Queen's University Belfast. 
http://questor.qub.ac.uk/REMEDIATE/. Authors will also like to express gratitude towards Jie Chen, Department of Earth Sciences, University of Torino for helping with micro-XRF and SEM analysis. Sincere thanks to Giorgio Carbotta and Prof. Piergiorgio Rossetti, Department of Earth Sciences, University of Torino for helping with sampling and teaching Petromod.

\section{References}

BARGE (2010). UBM procedure for the measurement of the inorganic contaminant bioaccessibility from solid matrices.

Barsby, A., McKinley, J.M., Ofterdinger, U., Young, M., Cave, M.R., and Wragg, J. (2012). Bioaccessibility of trace elements in soils in Northern Ireland. Sci. Total Environ. 433, 398-417.

Basta, N.T., Ryan, J.A., and Chaney, R.L. (2005). Trace Element Chemistry in Residual-Treated Soil. J. Environ. Qual. 34, 49-63.

Cave, M. R., Milodowski, A. E., \& Friel, E. N. (2004). Evaluation of a method for identification of host physicochemical phases for trace metals and measurement of their solid-phase partitioning in soil samples by nitric acid extraction and chemometric mixture resolution. Geochemistry: Exploration, Environment, Analysis, 4, 71-86.

Chang, Winston. (2013). R Graphics Cookbook. Farnham: O’Reilly.

Cipullo, S., Snapir, B., Tardif, S., Campo, P., Prpich, G., and Coulon, F. (2018). Insights into mixed contaminants interactions and its implication for heavy metals and metalloids mobility, bioavailability and risk assessment. Sci. Total Environ. 645, 662-673.

Cossio, R., Borghi, A. \& Ruffini, R. (2002). Quantitative modal determination of geological samples based on X-ray multielemental map acquisition. Microsc Microanal 8, 139-149.

Cox, S.F., Chelliah, M.C.M., McKinley, J.M., Palmer, S., Ofterdinger, U., Young, M.E., Cave, M.R., and Wragg, J. (2013). The importance of solid-phase distribution on the oral bioaccessibility of $\mathrm{Ni}$ and $\mathrm{Cr}$ in soils overlying Palaeogene basalt lavas, Northern Ireland. Environ. Geochem. Health $35,553-567$. 
540 Cox, S.F., Rollinson, G., and McKinley, J.M. (2017). Mineralogical characterisation to improve 541 understanding of oral bioaccessibility of $\mathrm{Cr}$ and $\mathrm{Ni}$ in basaltic soils in Northern Ireland. J. Geochem. 542 Explor. 183, 166-177.

543 Denys, S., Tack, K., Caboche, J., and Delalain, P. (2009). Bioaccessibility, solid phase distribution, 544 and speciation of $\mathrm{Sb}$ in soils and in digestive fluids. Chemosphere 74, 711-716.

545 Denys, S., Caboche, J., Tack, K., Rychen, G., Wragg, J., Cave, M., Jondreville, C., and Feidt, C. 546 (2012). In Vivo Validation of the Unified BARGE Method to Assess the Bioaccessibility of 547 Arsenic, Antimony, Cadmium, and Lead in Soils. Environ. Sci. Technol. 46, 6252-6260.

548 Dino, G.A., Mehta, N., Rossetti, P., Ajmone-Marsan, F., and De Luca, D.A. (2018). Sustainable 549 approach towards extractive waste management: Two case studies from Italy. Resour. Policy. 550 https://doi.org/10.1016/j.resourpol.2018.07.009 (in press).

551 Fiorentini, M.L., and Beresford, S.W. Role of volatiles and metasomatized subcontinental 552 lithospheric mantle in the genesis of magmatic $\mathrm{Ni}-\mathrm{Cu}-\mathrm{PGE}$ mineralization: insights from in situ $\mathrm{H}$, $553 \mathrm{Li}, \mathrm{B}$ analyses of hydromagmatic phases from the Valmaggia ultramafic pipe, Ivrea-Verbano Zone 554 (NW Italy). Terra Nova 20, 333-340.

555 Foulkes, M., Millward, G., Henderson, S., and Blake, W. (2017). Bioaccessibility of U, Th and Pb 556 in solid wastes and soils from an abandoned uranium mine. J. Environ. Radioact. 173, 85-96.

557 Gál, J., Hursthouse, A., and Cuthbert, S. (2007). Bioavailability of arsenic and antimony in soils 558 from an abandoned mining area, Glendinning (SW Scotland). J. Environ. Sci. Health Part A 42, $559 \quad 1263-1274$

560 Golia, E.E., Dimirkou, A., and Mitsios, I.K. (2008). Influence of Some Soil Parameters on Heavy 561 Metals Accumulation by Vegetables Grown in Agricultural Soils of Different Soil Orders. Bull. 562 Environ. Contam. Toxicol. 81, 80-84.

563 Hamilton, E.M., Barlow, T.S., Gowing, C.J.B., and Watts, M.J. (2015). Bioaccessibility 564 performance data for fifty-seven elements in guidance material BGS 102. Microchem. J. 123, 131565138. 
Holzheid, A., and Lodders, K. (2001). Solubility of copper in silicate melts as function of oxygen and sulfur fugacities, temperature, and silicate composition. Geochim. Cosmochim. Acta 65, 19331951.

ISO 10390, 2005. Soil quality - Determination of pH. 7pp, available at https://www.iso.org/standard/40879.html.

Kumpiene, J., Giagnoni, L., Marschner, B., Denys, S., Mench, M., Adriaensen, K., Vangronsveld, J., Puschenreiter, M., and Renella, G. (2017). Assessment of Methods for Determining Bioavailability of Trace Elements in Soils: A Review. Pedosphere 27, 389-406.

Lim, M., Han, G.-C., Ahn, J.-W., You, K.-S., and Kim, H.-S. (2009). Leachability of Arsenic and Heavy Metals from Mine Tailings of Abandoned Metal Mines. Int. J. Environ. Res. Public. Health 6, 2865-2879.

Maddaloni, M., Lolacono, N., Manton, W., Blum, C., Drexler, J., and Graziano, J. (1998). Bioavailability of soilborne lead in adults, by stable isotope dilution. Environ. Health Perspect. 106, $1589-1594$.

Martin, T.A., and Ruby, M.V. (2004). Review of in situ remediation technologies for lead, zinc, and cadmium in soil. Remediat. J. 14, 35-53.

Mehta, N., Dino, G.A., Ajmone-Marsan, F., Lasagna, M., Romè, C., and De Luca, D.A. (2018). Extractive waste management: A risk analysis approach. Sci. Total Environ. 622-623, 900-912.

Ministero dell'ambiente e della tutela del territorio. (2006). Gazzetta Ufficiale n. 88 of 14 Aprile 2006 Decreto Legislativo 3 aprile 2006, n. 152"Norme in materia ambientale." (Norms concerning the environment.)

Ono, F.B., Penido, E.S., Tappero, R., Sparks, D., and Guilherme, L.R.G. (2016). Bioaccessibility of $\mathrm{Cd}$ and $\mathrm{Pb}$ in tailings from a zinc smelting in Brazil: implications for human health. Environ. Geochem. Health 38, 1083-1096.

Oomen AG (2000). Determination of oral bioavailability of soil-borne contaminants. University of Utrecht. 
Palumbo-Roe, B., and Klinck, B. (2007). Bioaccessibility of arsenic in mine waste-contaminated soils: A case study from an abandoned arsenic mine in SW England (UK). J. Environ. Sci. Health Part A 42, 1251-1261.

Palumbo-Roe, B., Wragg, J., and Cave, M. (2015). Linking selective chemical extraction of iron oxyhydroxides to arsenic bioaccessibility in soil. Environ. Pollut. 207, 256-265.

Paustenbach, D.J. (2000). The Practice of Exposure Assessment: A State-of-the-Art Review. J. Toxicol. Environ. Health Part B 3, 179-291.

Peijnenburg, W.J.G.M., and Jager, T. (2003). Monitoring approaches to assess bioaccessibility and bioavailability of metals: Matrix issues. Ecotoxicol. Environ. Saf. 56, 63-77.

Pelfrêne, A., Waterlot, C., Mazzuca, M., Nisse, C., Cuny, D., Richard, A., Denys, S., Heyman, C., Roussel, H., Bidar, G., et al. (2012). Bioaccessibility of trace elements as affected by soil parameters in smelter-contaminated agricultural soils: A statistical modeling approach. Environ. Pollut. 160, 130-138.

Pokrovsky, O.S., and Schott, J. (2000). Kinetics and mechanism of forsterite dissolution at $25^{\circ} \mathrm{C}$ and $\mathrm{pH}$ from 1 to 12 . Geochim. Cosmochim. Acta 64, 3313-3325.

Pouchou, J. L. \& Pichoir, F. (1988). Determination of mass absorption coefficients for soft X-rays by use of the electron microprobe. In: Newbury, D.E. (ed.) Microbeam Analysis. San Francisco, CA: San Francisco Press, pp. 319-324.

Quantin, C., Ettler, V., Garnier, J., and Šebek, O. (2008). Sources and extractibility of chromium and nickel in soil profiles developed on Czech serpentinites. Comptes Rendus Geosci. 340, 872882.

Redler, C., Johnson, T.E., White, R.W., and Kunz, B.E. Phase equilibrium constraints on a deep crustal metamorphic field gradient: metapelitic rocks from the Ivrea Zone (NW Italy). J. Metamorph. Geol. 30, 235-254. 
Reis, A.P., Patinha, C., Wragg, J., Dias, A.C., Cave, M., Sousa, A.J., Costa, C., Cachada, A., Silva, E.F. da, Rocha, F., et al. (2014). Geochemistry, mineralogy, solid-phase fractionation and oral bioaccessibility of lead in urban soils of Lisbon. Environ. Geochem. Health 36, 867-881.

Rossetti P., Dino G.A., Biglia G., Costa E. (2017). Characterization of secondary raw materials from mine waste: a case study from the Campello Monti $\mathrm{Ni} \pm \mathrm{Cu} \pm \mathrm{Co} \pm \mathrm{PGE}$ mining site (Western Alps, Italy). Sardinia 2017 / Sixteenth International Waste Management and Landfill Symposium / 2 - 6 October 2017. S. Margherita di Pula, Cagliari, Italy / @ 2017 by CISA Publisher, Italy. ISSN 2282-0027. pp.13. (Proceedings).

Ruby, M.V., Schoof, R., Brattin, W., Goldade, M., Post, G., Harnois, M., Mosby, D.E., Casteel, S.W., Berti, W., Carpenter, M., et al. (1999). Advances in Evaluating the Oral Bioavailability of Inorganics in Soil for Use in Human Health Risk Assessment. Environ. Sci. Technol. 33, 36973705.

Teien, H.-C., Kroglund, F., Atland, A., Rosseland, B.O., and Salbu, B. (2006). Sodium silicate as alternative to liming-reduced aluminium toxicity for Atlantic salmon (Salmo salar L.) in unstable mixing zones. Sci. Total Environ. 358, 151-163.

U.S. EPA 3051 A, 2007. Washington, DC, Microwave assisted acid digestion of sediments, sludges, soils, and oils.

U.S. EPA 6010 C, 2007. Washington, DC, Inductivelycoupled plasma-atomic emission spectrometry.

Venturelli, G., Contini, S., Bonazzi, A., and Mangia, A. (2016). Weathering of ultramafic rocks and element mobility at Mt. Prinzera, Northern Apennines, Italy. Mineral. Mag. 61, 765-778.

Wickham H (2007). Reshaping Data with the Reshape Package. J Stat Softw, 21(12), 1-20.

Wickham H (2009). ggplot2: Elegant Graphics for Data Analysis. useR. Springer-Verlag.

Wragg, J. (2005). A study of the relationship between Arsenic bioaccessibility and its solid phase distribution in Wellingborough soils. PhD Thesis, University of Nottingham. 
641 Yao, Q., Wang, X., Jian, H., Chen, H., and Yu, Z. (2015). Characterization of the Particle Size 642 Fraction associated with Heavy Metals in Suspended Sediments of the Yellow River. Int. J. 643 Environ. Res. Public. Health 12, 6725-6744.

644 Yunmei, Y., Yongxuan, Z., Williams-Jones, A.E., Zhenmin, G., and Dexian, L. (2004). A kinetic 645 study of the oxidation of arsenopyrite in acidic solutions: implications for the environment. Appl. 646 Geochem. 19, 435-444.

647 